\title{
Introdução à Mecânica Quântica: uma proposta de minicurso para \\ o ensino de conceitos e postulados fundamentais
}

\author{
Introduction to Quantum Mechanics: a \\ proposal for a short course for \\ the teaching of fundamental concepts and \\ postulates
}

Carlos Raphael Rocha

Victoria Elniecave Herscovitz

Marco Antonio Moreira

\section{Resumo}

Analisa-se a viabilidade de uma proposta pedagógica de curta duração para o ensino de Mecânica Quântica (MQ) em nível introdutório. Foi elaborado um minicurso visando criar situações propícias para o ensino dos conceitos fundamentos contidos nos primeiros princípios da MQ. O minicurso teve três apresentações, a primeira ocorrendo no II Encontro Estadual de Ensino de Física, realizado na Universidade Federal do Rio Grande do Sul, em Porto Alegre, RS, e as outras duas na VII Semana da Física, na Universidade do Estado de Santa Catarina, em Joinville, SC, Brasil.

Palavras-chave: Mecânica Quântica, proposta pedagógica, conceitos fundamentais.

\section{Abstract}

We analyze the viability of a short-term pedagogical proposal about Quantum Mechanics teaching at an introductory level. The course was intended to create situations to enhance the acquisition and retention of the fundamental 
concepts present in the first postulates of Quantum Mechanics. The short-term course had three presentations, the first one in the II State Meeting on Physics Teaching, at the Federal University of Rio Grande do Sul, at UFRGS, Porto Alegre, RS and the other two during a physics meeting at the State University of Santa Catarina, UDESC, Joinville, SC, Brazil.

Keywords: Quantum Mechanics, pedagogical proposal, fundamental concepts.

\section{Introdução}

O desenvolvimento da Mecânica Quântica (MQ) no século passado ocasionou uma importante alteração no modo científico de pensar. Esta alteração produziu grandes implicações tecnológicas e educacionais, tanto que não se pode hoje deixar de incluir o ensino de $\mathrm{MQ}$ em cursos de graduação relacionados à Física. Observa-se, porém, que em vários cursos o ensino desta disciplina trabalha muito com a resolução de problemas envolvendo equações diferenciais e pouco com aspectos relacionados aos conceitos fundamentais e postulados da $\mathrm{MQ}$.

Adicionalmente, há uma necessidade inerente à reforma curricular do Ensino Médio, de apresentar-se, nas disciplinas de Física entre outras, teorias científicas desenvolvidas mais recentemente. Pode-se dizer que, na maioria dos cursos de nível médio, a Física que se ensina nas escolas está defasada de cerca de dois séculos. Para que se saliente o desenvolvimento contínuo da ciência, faz-se necessário atualizar constantemente o currículo educacional e para que esta atualização chegue às salas de aula do Ensino Médio é primordial que haja um adequado preparo dos professores, propiciando que estes estejam seguros de seu conhecimento.

Cursos complementares para professores e alunos de licenciatura ou de outras áreas, de duração menor do que a duração usual curricular, em que sejam abordados aspectos de MQ numa linguagem menos matemática, mas fiel à Teoria são, então, alternativas recomendáveis. Esta linha tem sido adotada em Projeto em execução por alguns professores e estudantes de PósGraduação em Ensino de Física do IFUFRGS. Uma destas propostas, desenvolvida por Greca et al. (2001), apresenta um módulo instrucional com duração aproximada de 24 horas-aula (12 sessões) que foi oferecido a estudantes de Física Geral de cursos de Engenharia, como forma de levá-los a compreender as bases de várias implicações tecnológicas recentes e de impacto, da teoria. Isto porque a MQ interessa não somente aos físicos, mas está, também, na base de desenvolvimentos de várias áreas, como as de engenharia, informação, comunicação e saúde, entre muitas outras que utilizam tecnologia em seu cerne. Tal abordagem muito pouco recorreu a desenvolvimentos matemáticos, preocupando-se mais com aspectos de compreensão de determinados fenômenos 
não explicados pela Física Clássica, mostrando-se positiva tanto nos aspectos motivadores, como nos de compreensão dos fenômenos enfocados.

Outra proposição, a atual, é a de que uma abordagem da MQ que enfoque os primeiros conceitos e postulados da Teoria pode ser uma via de acesso a esta área da Física Moderna, para o Ensino Médio. Assim, o que se busca neste trabalho é analisar a viabilidade de um projeto pedagógico de curta duração para o ensino de $M Q$, focado nos primeiríssimos princípios desta teoria e oferecido a professores de Física em exercício no Ensino Médio ou em formação. Outrossim, deseja-se verificar quais dos tópicos apresentados são de interesse do público-alvo e se tais tópicos podem ser adequadamente trabalhados junto a alunos de Ensino Médio. Os princípios fundamentais da $\mathrm{MQ}$ abordados foram selecionados visando preencher uma lacuna que perdura, às vezes, mesmo após a conclusão pelos licenciados, do curso de graduação. Isto porque, como já citado, em vários cursos de graduação são mais salientados certos aspectos matemáticos desta teoria (em que os alunos encontram dificuldades), faltando tempo para uma discussão mais aprofundada da parte conceitual, importante para a compreensão de qualquer princípio em toda teoria e especialmente nesta, pelo ineditismo não intuitivo. Procurou-se, além disto, levantar informação sobre outros tópicos que estimulassem o interesse pelo conhecimento e ensino de $M Q$.

Em suma, o principal intuito do minicurso foi o de promover uma complementação ao estudo da $M Q$, sob enfoque pouco explorado em cursos de licenciatura e, ao mesmo tempo, analisar a viabilidade e o interesse de uma proposta pedagógica menos tradicional para o ensino dos princípios básicos da $\mathrm{MQ}$, sem a necessidade de conhecimentos prévios sobre o assunto, e que pudesse ser um veículo para a promoção da atualização curricular.

Para analisar tais pontos o mini-curso foi apresentado três vezes, em duas situações distintas, conforme exposto adiante.

\section{Fundamentação teórica}

As manifestações dos participantes no decorrer dos mini-cursos foram analisadas utilizando-se elementos da Teoria da Aprendizagem Significativa de David Ausubel e da Teoria dos Campos Conceituais de Gerárd Vergnaud.

Segundo Ausubel (1968), se fosse possível reduzir a psicologia educacional a um princípio, este seria: "o fator mais importante a contribuir para o aprendizado é aquilo que o aprendiz já sabe". Ao educador cabe, então, averiguar o que o aprendiz sabe e ensinar de acordo. Esse conhecimento prévio normalmente funciona como ancoradouro cognitivo para a aquisição significativa de novos conhecimentos, mas pode também atuar como obstáculo epistemológico. 
Ao iniciar o estudo da MQ, o aprendiz já possui um conhecimento intuitivo oriundo da Mecânica Clássica (seja pelo aprendizado formal ou pela vivência no cotidiano). Como a MQ, contudo, não é um caso particular da Mecânica Clássica, deve-se buscar abordá-la de forma que não se apóie em fundamentos clássicos. No entanto, a utilização de analogias entre a MQ e a Mecânica Clássica pode ser útil para a compreensão da estrutura da $M Q$ sem que com isto se pretenda explicar os fenômenos quânticos com base em princípios clássicos.

Como todo processo de aprendizagem, a aprendizagem significativa também é uma negociação (e aquisição) de significados, existindo algumas condições iniciais para que possa ocorrer, a saber (op. cit., p.1):

- a estrutura cognitiva do aprendiz deve conter idéias relevantes com as quais o novo material deve se relacionar;

- a relação com esse conhecimento prévio deve ser não-arbitrária e não-literal.

Outra condição para a ocorrência da aprendizagem significativa é que o aprendiz deve apresentar uma pré-disposição para aprender. Porém, não se deve confundir pré-disposição com motivação, no sentido de gostar, de entusiasmar-se. 0 aprendiz pode não estar motivado para aprender, mas predisposto. Vale salientar que de nada adianta o material ser potencialmente significativo se o aluno não estiver disposto a relacioná-lo interativamente com seus subsunçores, ou seja, com conhecimentos prévios que servem de "ancoradouro" cognitivo para o novo conhecimento. É importante observar que, como o processo é interativo, além de dar significado ao novo conhecimento, o subsunçor também se modifica, adquirindo novos significados, ficando mais estável, mais elaborado, diferenciado.

Outro conceito muito importante introduzido por Ausubel é o de organizador prévio (2000, p. 11). O organizador prévio é um recurso pedagógico que pretende suprir eventuais deficiências de subsunçores necessários para que ocorra aprendizagem significativa. Ele serve de ponte entre aquilo que o aluno já sabe e aquilo que deveria saber para que pudesse aprender de forma significativa e deve ser apresentado em um nível de abstração, generalidade e inclusividade mais alto que o do novo material a ser aprendido (ibid.).No caso em foco, o aprendiz vem à aula com conhecimento criado a partir de vivências explicadas pela Mecânica Clássica, as quais podem servir para construir organizadores prévios, mas que, na nossa perspectiva, devem servir como subsunçores provisórios que visem facilitar o aprendizado da MQ sem a necessidade de se apoiar em "pilares clássicos".

Apesar de ter sido aluno de Piaget, Vergnaud foca seu estudo no sujeito em situação. São as situações que darão sentido aos conceitos (Moreira, 2002, p. 10). Um conceito, porém, não é uma mera definição. Ele se refere a um conjunto de situações, envolve um conjunto de diferentes invariantes operatórios e suas propriedades podem ser expressas por diferentes representações 
simbólicas e lingüísticas (Vergnaud, 1999, p. 177). Além das situações, os conceitos também são constituídos por invariantes operatórios e representações. Os invariantes operatórios definem a operacionalidade e o significado do conceito (Moreira, 2002, p. 10). São conhecimentos-em-ação: teoremas-em-ação (regras que o sujeito crê que são válidas sobre a realidade) e conceitos-emação (propriedades, atributos, pertinentes à situação). As representações são utilizadas para indicar simbolicamente os invariantes e, assim, representar as situações e os procedimentos para lidar com elas (ibid.).

Outro aspecto da teoria de Vergnaud é concernente ao fato de que o aprendiz leva, em geral, algum tempo para dominar determinado campo conceitual. Com isto, considerando a MQ como um campo conceitual, pode-se concluir que em um primeiro contacto com o assunto o estudante dará seus primeiros passos nesse campo, ou seja, começará a dar significados aos principais conceitos e postulados da MQ. Esses primeiros passos são extremamente importantes para uma aprendizagem significativa. Ademais, mesmo que o aprendiz já tenha tido a oportunidade de estudar alguns aspectos da $\mathrm{MQ}$, um curso de curta duração sobre os princípios básicos da MQ propiciará vincular seus conhecimentos anteriores aos postulados, permitindo elevar seu nível de compreensão sobre esta teoria. Em paralelo, um curso de curta duração com tal enfoque conduzirá a uma visão mais correta do que é a $M Q$, quando seguido de cursos mais longos.

\section{A proposta}

A proposta inicial do projeto foi a de preparar um minicurso destinado a licenciados e licenciandos de Física, para avaliar a viabilidade de uma modalidade de ensino introdutório ou complementar de $\mathrm{MQ}$, com foco em conceitos fundamentais e primeiros postulados da Teoria, acompanhados de algumas de suas marcantes implicações. A expectativa é de que isto possa servir de estímulo e apoio para que os professores passem a incluir tópicos desta natureza em suas aulas no Ensino Médio.

O mini-curso foi apresentado três vezes, uma delas na UFRGS e duas outras na UDESC, conforme detalhado mais adiante. A ementa é apresentada a seguir.
Fundamentos da Mecânica Quântica
○ Introdução
- Experimentos de dupla fenda
- Superposição de ondas

R. B. E. C. T., vol 3, núm 1, jan./abr. 2010 


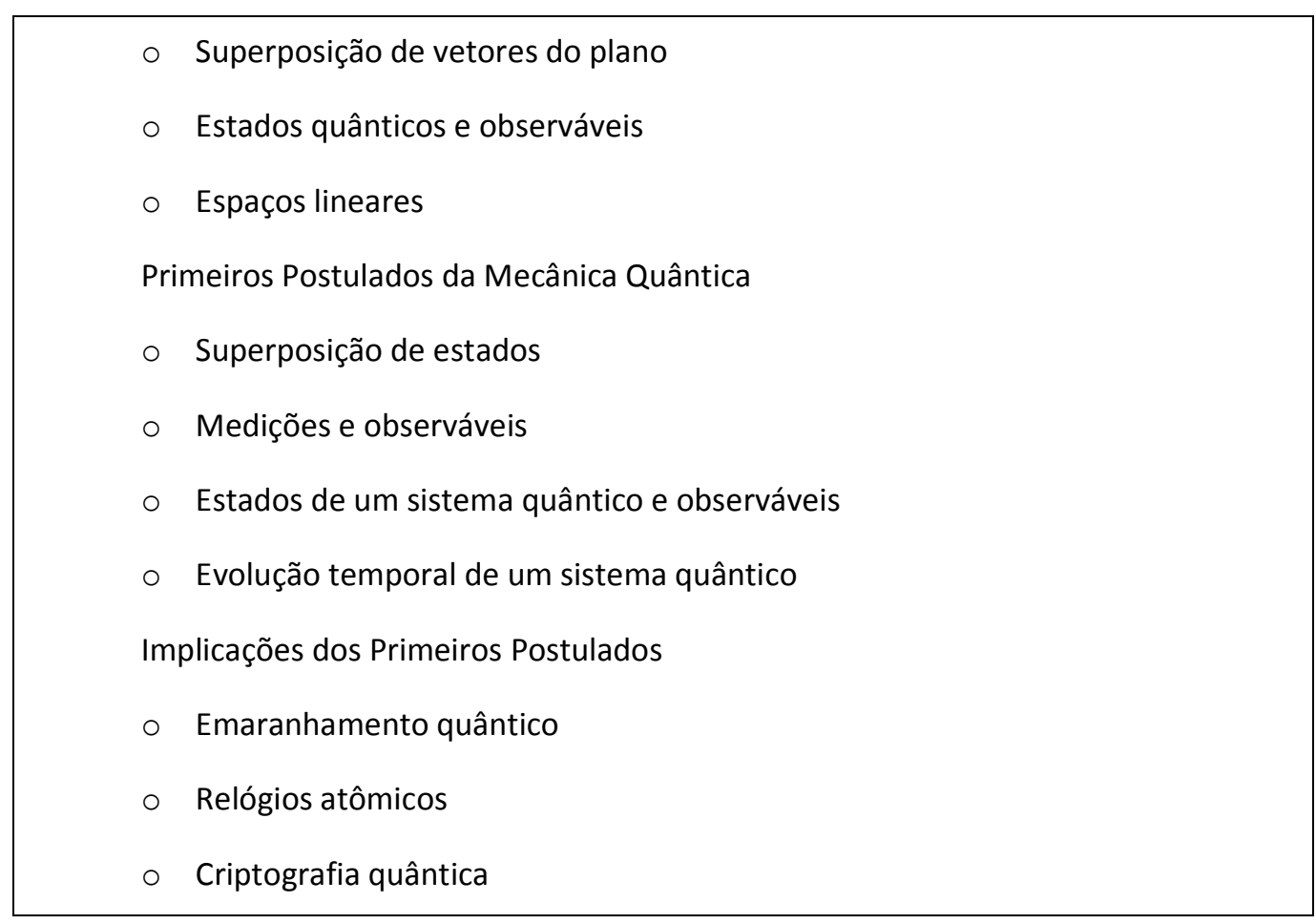

Por se tratar de um curso de curta duração, optou-se por trabalhar com apenas alguns dos conceitos da MQ e com implicações referentes somente aos primeiros postulados. Não houve pretensão de avaliar formalmente a aprendizagem dos participantes no transcorrer do curso, mas seu interesse pelo conteúdo e seu envolvimento com o mesmo foram observados. A rigor, o objeto de avaliação foi o curso em si, no entanto, em todo o decorrer das atividades, os alunos foram instados a apresentar questionamentos e a responder perguntas, para promover a participação dos mesmos no assunto, tornando-os agentes ativos no processo de aprendizagem.

Já na Introdução, buscou-se apresentar alguma situação que pudesse motivar os alunos para o aprendizado da MQ. Para tanto, apresentou-se um exemplo do fenômeno de emaranhamento quântico, através do trabalho de Ursin et al. (2007) em que os autores conseguiram obter um par de fótons emaranhados (em termos de auto-estados de polarização) distanciados de $144 \mathrm{~km}$.

No curso ministrado na UFRGS foram trabalhados na primeira aula os tópicos relacionados aos Fundamentos da MQ (Introdução, Experimentos de Dupla Fenda, Superposição de Ondas e de Vetores do Plano, Estados Quânticos e Observáveis e Espaços Lineares). Neste encontro buscou-se formar alguns conceitos que pudessem servir de âncora para a discussão e aprendizado subseqüente de alguns dos postulados da MQ. Foram apresentados vários conceitos característicos de espaços lineares, a saber, os de vetor, superposição linear de vetores, operador, auto-vetores, autovalores e autofunções, para servirem como organizadores prévios. Outros 
itens, como o do Experimento de Dupla Fenda, funcionariam já como subsunçores para a aceitação dos primeiros postulados. Na segunda aula foram apresentados alguns dos primeiros postulados da $\mathrm{MQ}$, na descrição de Schrödinger, a saber, o referente ao estado quântico como depositário das informações sobre as grandezas físicas de um sistema quântico em um dado instante de tempo, o que denota a correspondência entre grandezas físicas e operadores lineares auto-adjuntos, o relativo ao colapso do vetor de estado no ato de medida de um observável físico e o da evolução temporal do estado de um sistema quântico, regida pela equação de Schrödinger. Tais postulados foram trabalhados, em sua maior parte, de forma conceitual e com exemplos, visando preencher lacunas existentes ou remanescentes, mesmo após a conclusão do ensino formal pelos participantes. Na última aula, foram apresentadas algumas aplicações importantes e atuais da $\mathrm{MQ}$, implicações formalmente simples, embora surpreendentes, dos primeiros postulados trabalhados, como o emaranhamento quântico e a criptografia quântica, para tentar promover a contextualização, através da utilização dos conceitos abordados.

Nos cursos apresentados na UDESC, os dois primeiros encontros supracitados foram condensados em uma única apresentação e a segunda aula correspondeu à terceira anterior.

Além disto, foram propostos exercícios aos alunos, para fixação do conteúdo abordado, exercícios estes resolvidos e discutidos na própria aula. Procurou-se também instigar os alunos a participar criticamente e a se interessar pelo assunto com questões do tipo "Pense !", fazendo com que conseguissem perceber algumas "estranhezas" do mundo quântico.

\section{A implementação do minicurso}

Após a elaboração da proposta do curso e do material didático a ser entregue aos participantes, o minicurso foi ministrado três vezes, em duas ocasiões distintas, em setembro de 2007. O primeiro deles foi apresentado no II Encontro Estadual de Ensino de Física (II EEEFis), no Instituto de Física da UFRGS, em Porto Alegre, RS. Tal mini-curso teve seis horas-aula divididas em três encontros de igual duração, nos dias 13, 14 e 15 de setembro. Neste curso, o público-alvo esteve constituído de professores de Física (profissionais em exercício, a maioria no Ensino Médio) e de licenciandos de Física, quase todos do Rio Grande do Sul.

Estavam inscritos no mini-curso, antecipadamente, 15 participantes, mas foram aceitas no dia do início do Encontro outras sete inscrições, totalizando a presença de 22 alunos. A estrutura disponibilizada para ministrar o curso constou de um laboratório de informática equipado com 20 computadores (capazes de rodar as simulações utilizadas nas aulas) e um projetor multimídia, acoplado a um dos computadores. 
Os outros dois mini-cursos foram apresentados na VII Semana da Física, na Universidade do Estado de Santa Catarina, em Joinville, SC. Estes cursos tiveram quatro horas-aula de duração cada, divididas em dois encontros, e ocorreram nos dias 19 e 20 de setembro. A comissão organizadora do evento ofertou 20 vagas para cada turma, mas a procura pelo curso (sobretudo para a primeira turma) foi tamanha, que resultou em uma fila de espera com mais de 40 pessoas. Para a primeira turma, foram selecionados 23 alunos e para a segunda, 16. Por ser um evento acadêmico (promovido pela Universidade), o público-alvo era formado por estudantes do curso de Licenciatura em Física da UDESC, público este que se revelou heterogêneo, incluindo tanto alunos dos primeiros semestres do curso, como dos últimos. Esta diversidade possibilita analisarse a importância do conhecimento de conteúdos prévios, para a proposta.

Estes dois cursos foram, ambos, ministrados em dois ambientes distintos. No primeiro dia, utilizou-se um laboratório de informática com 15 computadores, enquanto no segundo dia do curso o encontro ocorreu em uma sala de seminários equipada com um computador portátil e um projetor multimídia.

Em nenhum dos mini-cursos, houve solicitação de pré-requisitos (além de serem oferecidos no âmbito universitário). Considerou-se que, em princípio, se é possível ensinar MQ a alunos sem que eles tenham tido um contato inicial com a mesma, é viável também, ter alunos universitários com níveis de formação distintos, compartilhando o mesmo curso.

Como dito anteriormente, não houve avaliação formal da aprendizagem dos alunos participantes, mas, com o fito de analisar a adequação e a viabilidade do curso, foi programado e realizado um registro das ocorrências em sala de aula, no decorrer das apresentações (diário de bordo) com o intuito de colher dados para uma análise posterior.

\section{Resultados}

Não havendo a intenção de avaliar a aprendizagem, o relato sobre as atividades desenvolvidas e os questionamentos formulados pelos alunos no decorrer dos três mini-cursos são apresentados de forma conjunta, considerando ser a proposta, única, e não especialmente adequada para análises isoladas.

Material didático produzido especialmente para as aulas foi distribuído aos alunos no início de cada encontro e um projetor multimídia foi utilizado durante toda a duração do curso, para apresentação do material, de modo a tornar mais atraente a atividade desenvolvida.

Visando motivar os alunos e criar uma condição de pré-disposição para o aprendizado, as aulas dos minicursos foram iniciadas com informação sobre a verificação experimental de estados emaranhados (fortemente correlacionados) separados espacialmente por $144 \mathrm{~km}$ (Ursin et al., 
2007). Apesar de se tratar de evento recente e fortemente não-intuitivo, a menção não causou impacto sobre os alunos e nem os motivou a ponto de demonstrarem interesse no tópico. Como se considera que o emaranhamento quântico é uma das principais e mais marcantes aplicações atuais dos primeiros princípios da $\mathrm{MQ}$, concluiu-se pela modificação e aprimoramento da apresentação, em intervenções posteriores, para que se consiga o efeito esperado. Em princípio, a apresentação do emaranhamento quântico no estudo de conceitos fundamentais de $\mathrm{MQ}$, dadas as suas surpreendentes e não clássicas conseqüências, é um ótimo exemplo, pois decorre de modo simples de conceitos fundamentais, como o de estado de sistema quântico e de superposição linear de estados de sistemas quânticos.

Quanto aos experimentos de dupla fenda com ondas, com partículas clássicas e com partículas quânticas, além da descrição e explicação dos mesmos, foi usada uma simulação em computador $^{1}$ para enriquecer o aprendizado. Percebeu-se que, na discussão sobre o caso quântico, os participantes dos cursos não utilizavam o conceito de estado e a propriedade de superposição linear para a explicação dos eventos apresentados, mas sim, em geral, a dualidade onda-partícula (não enfatizada nos minicursos). Foi possível notar, também, que os conceitos quânticos mais básicos não pareciam bem arraigados nos participantes (embora muitos destes fossem professores ou alunos de final de curso de Licenciatura), pois na discussão dos experimentos, os alunos cometeram vários erros, demonstrando insegurança e falta de conhecimento (e preparo). Isto mostra que os subsunçores presentes na estrutura cognitiva dos alunos não eram adequados para ancorar uma explicação correta dos fenômenos quânticos. Depois de analisar o experimento com partículas quânticas em termos de "possibilidades", foi alentador verificar que os alunos conseguiam explicar melhor a existência de um padrão de interferência, mesmo quando o experimento era realizado com um único elétron sendo detectado a cada vez.

Para a superposição de ondas, os alunos receberam a tarefa de compor combinações que possibilitavam verificar esta propriedade. Foram apresentados, também, exemplos de superposições de ondas comuns no campo da Eletrônica, como as ondas triangulares. Verificou-se que os participantes apresentavam dificuldades na construção de gráficos em que era necessário somar duas (ou mais) ondas. Apesar disto, os alunos aceitaram facilmente que a superposição de duas ou mais ondas gera uma nova onda e que se multiplicarmos a função que representa uma onda por um escalar também será gerada uma onda. Tal compreensão é bastante útil para se

\footnotetext{
${ }^{1}$ Simulação disponível em

http://phet.colorado.edu/simulations/sims.php?sim=Quantum_Wave_Interference.
} 
possa fazer a transposição para a superposição linear de estados quânticos (organizador prévio). Nesta instância dos mini-cursos, os alunos utilizaram uma simulação em computador que possibilita alterar o comprimento de onda e a amplitude de duas ondas e observar a onda resultante na soma ${ }^{31}$. Também uma questão do tipo "Pense!" foi proposta aos alunos, a saber, "Qual a ligação entre a superposição de ondas e o resultado do experimento de dupla fenda com partículas quânticas?", com respostas bastante adequadas.

A superposição de vetores geométricos não gerou dúvidas. Possivelmente devido à familiaridade com a utilização freqüente de vetores em Matemática e a aplicação de vetores em Mecânica Clássica, os alunos acolheram prontamente a idéia de que a soma (usual) de dois vetores e a multiplicação de vetor por escalar resultam em outros vetores do mesmo espaço.

Mostrou-se, então, bastante simples, promover a generalização e a abstração das propriedades de ondas (funções) e de vetores geométricos, para espaços lineares. Revelando-se devidamente arraigado o conceito de superposição linear (de ondas e de vetores geométricos), buscou-se fazer a ligação com o conceito de superposição linear de estados de um sistema quântico.

Após utilizar a superposição de ondas e a de vetores geométricos como organizadores prévios do conhecimento sobre espaços lineares e de proceder-se à análise daquelas superposições sob enfoque mais amplo de vetores de um espaço linear, foram introduzidos os conceitos de estado quântico e de superposição linear de estados quânticos, salientando-se que, tal como ondas e vetores geométricos, os estados quânticos também podem ser superpostos, gerando outros estados quânticos, para o que foi importante o resultado da experiência de dupla fenda para elétrons. Fez-se, então, detida menção sobre o fato de que a caracterização do estado de um sistema quântico como vetor de um espaço linear conduz a conseqüências não explicáveis pela Mecânica Newtoniana (e explicáveis pela nova Teoria). Salientou-se que a propriedade de superposição linear dá conotação não clássica aos estados dos sistemas quânticos.

Questionamentos sobre a caracterização do estado de um sistema clássico e do de um sistema quântico, revelaram que a grande dificuldade dos alunos residia em não saber como obter informações a respeito. Contudo, ao induzir os alunos a pensar em medidas de propriedades físicas como modo de obter informação sobre o estado de objetos (sistemas) clássicos, foram transpostas várias das dificuldades reveladas pouco antes, inclusive para a caracterização de estados de sistemas quânticos. $\mathrm{O}$ uso deste específico conhecimento sobre um sistema clássico serviu como subsunçor para a MQ. Não foi, contudo, proposto (ou incentivado)

\footnotetext{
${ }^{1}$ Simulação disponível em http://www.colorado.edu/physics/2000/schroedinger/index.html.
} 
em qualquer momento que os alunos interpretassem os fenômenos quânticos com conceitos clássicos.

Vencido este ponto, foi introduzida, apenas como um simbolismo, sem maior rigor, a notação de Dirac para (vetores de) estados de sistemas quânticos. Foi ponto comum em todos os mini-cursos o grande impacto causado por esta notação. Como muitos dos alunos nunca haviam tido contato com ela, afirmavam inicialmente que era difícil entender e utilizar a simbologia e que não conseguiam compreender o seu significado. Porém, no transcorrer do curso, com a introdução e aplicação dos conceitos de estado e de observável, os alunos passaram a se habituar com a notação de Dirac e a considerá-la útil e, ao final, até já a utilizavam em suas perguntas. Percebeu-se que tal notação auxiliou na generalização de muitas das idéias que envolvem vetores de espaços lineares e estados de objetos quânticos.

Recorrendo novamente a uma simulação em computador do experimento de dupla fenda para elétrons, os alunos perceberam que a medida (da posição da partícula) é uma operação que pode alterar o padrão de interferência e, assim sendo, modificar o estado do objeto quântico em análise. Ficou perceptível, aqui, que a utilização das simulações em computador facilitou a compreensão dos conceitos quânticos trabalhados.

A seguir foi analisado o postulado relativo ao "colapso do vetor de estado no ato da medida", importante quesito dentre os primeiros princípios da MQ. Na discussão deste postulado, face aos questionamentos apresentados, foi possível perceber que os alunos compreenderam que esta premissa permite explicar conseqüências da medição observadas (experimentalmente), um dos principais objetivos do curso. Este foi um dos tópicos em que os participantes mais demonstraram interesse, possivelmente por estar constantemente presente em artigos, livros e filmes de divulgação científica ou fantasiosos, recentemente produzidos.

Com o tempo da segunda aula do minicurso apresentado na UFRGS praticamente esgotado, foi dada apenas uma rápida explanação sobre o postulado da evolução temporal dos estados de sistemas quânticos (Equação de Schrödinger), não tendo sido possível elaborar uma discussão a respeito, para bem compreendê-lo. Muitos alunos, mesmo considerando a existência de uma "lei" para a evolução temporal dos sistemas, afirmavam não ser possível determinar o estado de um sistema quântico em um instante posterior a um dado, face ao Princípio de Incerteza. Apesar de sua importância na MQ, o Princípio da Incerteza (que pode ser deduzido a partir dos primeiros postulados e, portanto, não ser considerado, de fato, um princípio), talvez devido a freqüentes citações e "usos" por leigos pode, em certos casos, tornar-se um obstáculo pedagógico para o aprendizado dos primeiros princípios da $\mathrm{MQ}$, por ser mal compreendido.

Na segunda aula do mini-curso apresentado no II EEEFis, um aluno comentou que achava muito interessante a abordagem utilizada. Segundo ele, praticamente todos os cursos de 
Mecânica Quântica que havia feito se caracterizaram por excessiva ênfase na resolução de problemas de autovalores para a equação de Schrödinger independente do tempo. Esta, aliás, é uma das reclamações que os alunos de disciplinas de $M Q$ de cursos de graduação, costumam apresentar.

Em geral, a abordagem dos mini-cursos, enfocando conceitos iniciais da $M Q$, foi bem recebida por outros alunos também ${ }^{41}$.

Quanto ao fenômeno do emaranhamento quântico, abordado após os conceitos principais, houve grande interesse pelo assunto e, sobretudo, em saber como eram produzidos os pares emaranhados. Também consideraram os alunos que as críticas ao emaranhamento quântico, feitas por Einstein (e Podolski e Rosen), não tinham sido totalmente rebatidas, ou seja, os alunos não "aceitaram" as soluções apresentadas ao paradoxo EPR, evidenciando certa resistência à aceitação da idéia de não-localidade na $M Q$ e, conseqüentemente, da plenitude da validade do princípio da superposição linear de estados. Contudo, como regra geral, os alunos manifestaram ser extremamente interessante estudar propriedades e fenômenos que não estão explicitados nos livros com os quais estão acostumados a trabalhar na graduação.

O tema relativo a relógios atômicos, em que se utilizou o emaranhamento quântico para melhorar a precisão do relógio, não instigou os alunos para a compreensão do fenômeno. Aliás, como não surtiu o efeito desejado na motivação dos alunos, esta aplicação mais atrapalhou, pelo tempo que ocupou, do que auxiliou no processo de aprendizagem. Como é recomendável apresentar o maior número possível de situações-problema para promover a conceitualização, este exemplo será eliminado, mas outros serão inseridos no material de apoio dos cursos. Além disto, algumas das situações ali constantes serão mais salientadas, para que se consiga melhor promover a aprendizagem significativa dos conceitos fundamentais da $\mathrm{MQ}$.

Quanto à criptografia quântica, a opção adotada de detalhar seus procedimentos conduziu a algumas dificuldades. O primeiro problema apresentado pelos alunos na compreensão do tópico foi a dificuldade de entender o conceito de monitoramento passivo. Apesar de ser um conceito simples e tido como intuitivo, sempre que o conceito vinha à tona era necessária uma nova, embora breve, explicação.

Escolheu-se como protocolo de transmissão de chaves criptográficas a ser apresentado aos alunos o protocolo BB84, que utiliza fótons polarizados para a criação da chave. A escolha

${ }^{1}$ Comentários elogiosos sobre a proposta do curso foram apresentados por alguns dos participantes, ao final dos dois primeiros encontros do minicurso oferecido na UFRGS 
priorizou a simplicidade do processo, embasado principalmente na superposição linear de estados de polarização da luz (horizontal e vertical).

No início os alunos aparentaram estar assustados com os passos utilizados no decorrer do processo de transmissão da chave criptográfica e, principalmente, com a quantidade de informações tornadas públicas sem que isso afetasse a segurança do processo. Este exemplo, entretanto, gerou um interesse muito grande, compensando assim as dificuldades apresentadas.

De fato, no mini-curso oferecido durante o II EEEFis, a última aula ocorreu em um sábado à tarde, dia e horário em que, muitas vezes, por ser a última atividade oferecida, alguns inscritos faltam, inclusive para retornar às cidades em que residem. Contudo, o interesse pelas atividades do mini-curso foi tão grande que apenas um dos inscritos, que desde o início informou ter um compromisso inadiável neste dia, não compareceu. Além disto, ao final do curso, muitos alunos continuaram na sala de aula fazendo perguntas a respeito dos diversos tópicos apresentados. Também ao final dos minicursos ministrados na VII SEFIS, alguns alunos passaram a repetir o processo de criptografia no quadro, enquanto outros discutiam o paradoxo EPR. Isto mostra que tais tópicos efetivamente motivaram os participantes para o aprendizado de MQ. Recomenda-se, então, que tais exemplos, constituindo-se em situações-problema muito atrativas, sejam utilizados para auxiliar na aprendizagem significativa dos conceitos neles presentes.

No encerramento dos minicursos, muitos alunos se mostraram agradecidos pela nova abordagem e comentaram julgar possível começar a trabalhar a MQ no Ensino Médio desta forma.

\section{Conclusão}

A receptividade dos tópicos abordados nos mini-cursos sugere que a ausência de discussões relativas aos conceitos fundamentais da MQ em cursos de graduação é sentida pelos alunos, dado o entusiasmo com que alguns pontos foram trabalhados. Em particular, os conceitos de estado e de superposição linear de estados de um sistema quântico não foram tidos como difíceis pelos alunos, face às situações que foram apresentadas. Isto nos estimula a buscar mais formas de trabalhar tais conceitos (e os demais princípios básicos) visando a conceitualização e, assim, fazer com que os professores tenham segurança ao abordar tópicos de Física Moderna com seus alunos.

Também se pode afirmar que os cursos apresentados trouxeram à tona exemplos de situações-problema úteis para a compreensão dos fenômenos quânticos. Mesmo que algumas das situações-problema utilizadas não tenham sido totalmente proveitosas, talvez por exigüidade de tempo, não se faz necessário descartar qualquer delas (exceto o enfoque do tema relativo aos 
relógios atômicos que, pelo motivo antes mencionado, será substituído por outro). Na verdade, o ideal seria a inclusão de ainda mais situações-problema, o que pode ser feito em cursos de não tão curta duração. Recordemos que, segundo Vergnaud, o grande número e diversidade de situações-problema em que os conceitos são aplicados favorece a conceitualização.

Situações como o emaranhamento quântico e os experimentos de dupla fenda se apresentaram como bons meios para a compreensão de alguns dos mais importantes conceitos da $\mathrm{MQ}$, tais como o de estado quântico, o de superposição linear de estados e o de colapso do vetor de estado, entre outros.

Crê-se, então, que as situações-problema utilizadas, agregadas a outras de igual relevância na $\mathrm{MQ}$, tais como o experimento de Stern-Gerlach e a polarização da luz, podem se apresentar como de suma importância para a compreensão dos principais conceitos desta teoria.

A utilização de simulações em computador se mostrou eficiente tanto para o interesse quanto para a compreensão dos fenômenos observados conduzindo, então, a agregar-se aplicativos também das novas situações-problema a serem incorporadas (minimizando o fato de que aparatos científicos de grande número de experimentos de MQ não é acessível aos centros universitários e escolas de Ensino Médio do país).

Mostrou-se ponto importante dos minicursos a não utilização de conceitos relativos à Mecânica Clássica para explicar os fenômenos quânticos. Desde o início, buscou-se trabalhar as situações-problema com conceitos oriundos diretamente da $M Q$, evitando que as leis da Física Clássica fossem equivocadamente arroladas como subsunçor para o aprendizado da MQ. Isto acabou por obviar alguns possíveis obstáculos epistemológicos para um prosseguimento no estudo da MQ.

A proposta aqui analisada permite, então, considerar que o ensino introdutório de $M Q$ pode ser feito sem o uso de conceitos da Mecânica Clássica e com o auxílio de inúmeras situações-problema em que os conceitos fundamentais da MQ são aplicados. Contudo, eventuais analogias com estruturas clássicas, tais como as de superposição de vetores no plano e de ondas, podem ser úteis para a construção de subsunçores para a MQ.

\section{Referências}

AUSUBEL, D. P. Acquisition and retention of knowledge: a cognitive view. Dordrecht: Kluwer Academic Publishers, 2000.

AUSUBEL, D. P. Educational psychology: a cognitive view. New York: Holt, Rinehart and Winston, 1968. 
GRECA, I. M., Moreira, M. A. e Herscovitz, V. E. Uma proposta para o ensino de Mecânica Quântica. Revista Brasileira de Ensino de Física, v. 23, n. 4, p. 444-457, dez. 2001.

MOREIRA, M. A. A teoria dos campos conceituais de Vergnaud, o ensino de ciências e a pesquisa nesta área. Investigações em Ensino de Ciências, Porto Alegre, v. 7, n. 1, p. 7-29, mar. 2002.

URSIN, R. et al. Entanglement-based quantum communication over 144 km. Nature Physics, v. 3, n. 7 , p. $481-486,2007$.

VERGAUND, G. ¿En qué sentido la teoría de los campos conceptuales puede ayudarnos para facilitar aprendizaje significativo? Investigações em Ensino de Ciências, Porto Alegre, v. 12, n. 2, p. 285-302, ago. 2007.

VERGAUND, G. A comprehensive theory of representation for mathematics education. Journal of Mathematical Behavior, Dordrecht, v. 17, n. 2, p. 167-181, June 1998.

Carlos Raphael Rocha. Instituto Federal de Santa Catarina. Professor do Instituto Federal de Santa Catarina, Campus Jaraguá do Sul. Doutorando do Programa de Pós-Graduação em Ensino de Física Instituto de Física da Universidade Federal do Rio Grande do Sul. carlos.raphael@ufrgs.br

Victoria Elnecave Herscovitz. Universidade Federal do Rio Grande do Sul. Instituto de Física. Professora Colaboradora do Programa de Pós-Graduação em Ensino de Física. Doutora em Física. victoria@if.ufrgs.br

Marco Antonio Moreira. Universidade Federal do Rio Grande do Sul. Instituto de Física. Professor do Departamento de Física e do Programa de Pós-Graduação em Ensino de Física. Doutor em Ensino de Ciências. moreira@if.ufrgs.br 